\title{
Respuesta al comentario del Dr. R. Acosta-Rojas
}

\section{Pablo BENITO-DUQUE}

Es obvio que las técnicas microquirúrgicas se han popularizado, pero también que la disponibilidad del material necesario para llevarlas a cabo, así como la práctica quirúrgica para aplicarlas no siempre están disponibles en todos los hospitales, a pesar de nuestros deseos. Esto se evidencia especialmente en países en vías de desarrollo, como he podido comprobar personalmente al colaborar como cirujano plástico en dichos países, en los que la posibilidad de recurrir a una técnica realizable con el mismo instrumental que puede usar un cirujano para reparar una hernia inguinal, puede ser la diferencia entre la amputación o la reconstrucción.

Coincido con el Dr. Acosta en su afirmación de que el tiempo operatorio es relativo en cualquier cirugía, pero poder disponer de la zona donante en la misma área quirúrgica de la zona a reconstruir es una ventaja objetiva en tiempo. Y si podemos llevar a cabo un procedimiento en la mitad de tiempo que otro, con un resultado equiparable, considero que es una ventaja de dicha técnica.

En contestación a las cuestiones planteadas por el Dr. Acosta:

1. El programa de movilización y rehabilitación de la extremidad lo dirigen especialistas en Rehabilitación, pero el paciente es supervisado por Cirugía Plástica para control de tolerancia del área reconstruida al apoyo-cizallamiento. Cuando consigue la deambulación, las revisiones se espacian.

2. Respecto a la ligadura de la vena safena menor, en la experiencia adquirida con el colgajo sural de flujo invertido, tanto en reconstrucciones de pequeña o de gran extensión, no hemos apreciado diferencia en la evolución del edema del colgajo, en aquellos pacientes en los que la realizamos.

3. En relación a la zona dadora, cuando valoramos las publicaciones con grandes injertos de piel en zona donante del colgajo, no puedo por menos que coincidir con el Dr. Acosta. En relación a los consejos de
Dhamangaonkar y col. (cubrirse estéticamente con pantalón largo), al ver las imágenes de su artículo, con injertos cubriendo la zona dadora (toda la pantorrilla), evidentemente representan una secuela estética grave. Pero no es el caso de los pacientes de nuestra serie, puesto que en todos ellos la secuela fue una cicatriz lineal en la pantorrilla, bien tolerada por todos (3 de ellos mujeres) que aunque idealmente sería preferible que no existiera, considero que no es una secuela exagerada para una reconstrucción del tipo de la que presentamos. Esto demuestra que una técnica puede mejorar conforme observamos sus puntos débiles. El uso de colgajos microquirúrgicos, fundamental en la reconstrucción de extremidad inferior, no está exento de cicatrices en zonas donantes habituales, como en el ALT, el colgajo lateral de brazo, etc., áreas igualmente importantes estéticamente. Sobre la posible influencia en el drenaje linfático con el levantamiento del colgajo sural, solo puedo decir que no he apreciado influencia alguna.

4. Respecto al seguimiento de la función, estudio de la marcha, puntos de presión en la zona reconstruida y casos de ulceras de presión, debo marcar en los pacientes de nuestra serie la importancia de un seguimiento clínico muy próximo. Es fundamental hacer comprender al rehabilitador el tipo de intervención realizada. En caso de úlceras plantares, solicitamos valoración por podólogo para el diseño de plantillas que mejoren el apoyo plantar. La evolución de los 2 pacientes tratados para reconstrucción plantar, fue hacia la deambulación sin restricciones después del injerto de piel plantar en el adulto, y del uso de plantillas específicas en la paciente de menor edad.

Damos las gracias al Dr. Acosta por sus comentarios que nos permiten aclarar dudas y ampliar explicaciones en determinadas áreas del artículo, así como intercambiar opiniones que enriquecen a nuestra especialidad. 